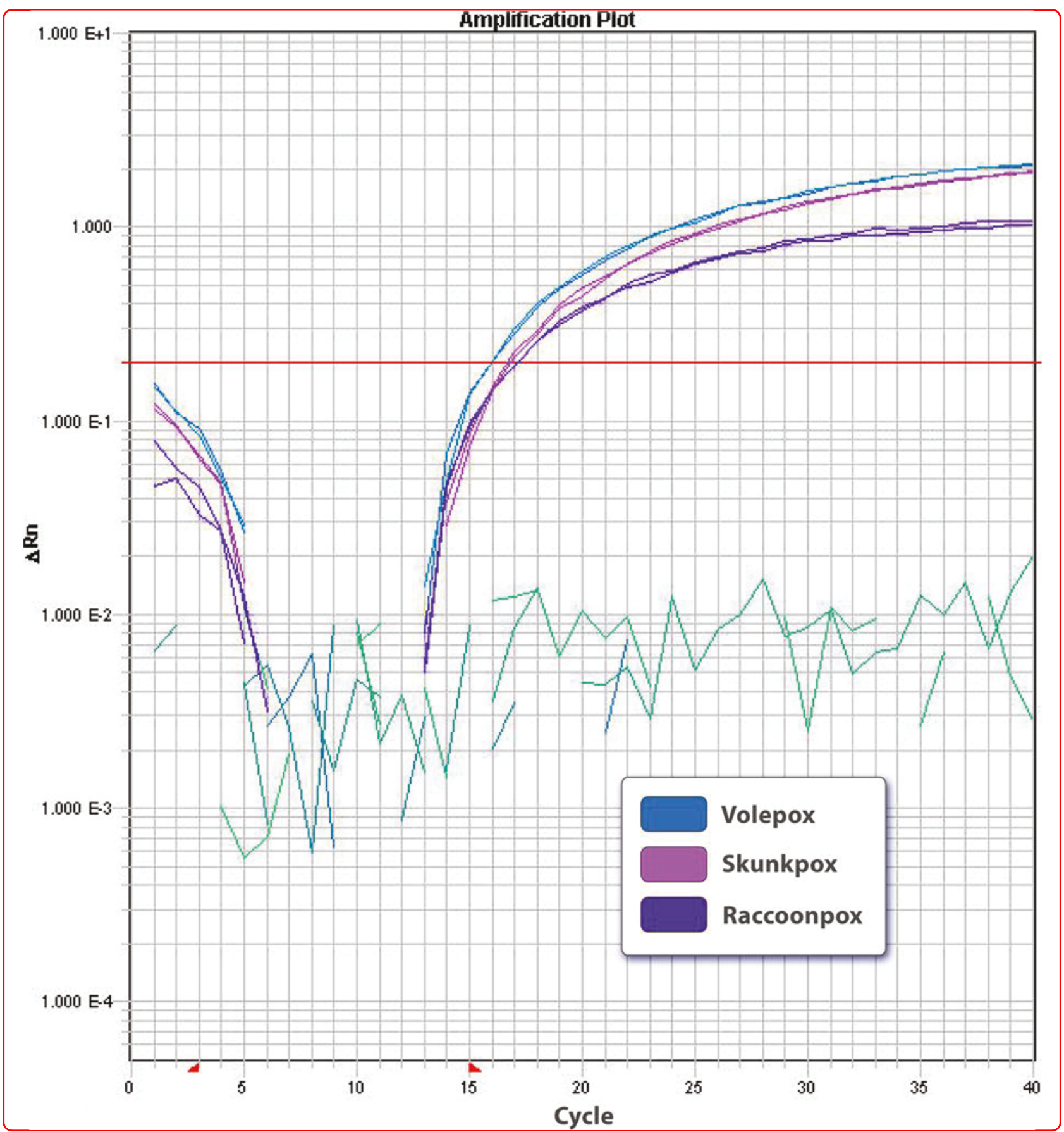

\title{
Detection of North American orthopoxviruses by real time-PCR
}

Gallardo-Romero et al. 


\title{
Detection of North American orthopoxviruses by real time-PCR
}

\author{
Nadia F Gallardo-Romero*, Andres Velasco-Villa, Sonja L Weiss, Ginny L Emerson, Darin S Carroll, \\ Christine M Hughes, Yu Li, Kevin L Karem, Inger K Damon and Victoria A Olson
}

\begin{abstract}
The prevalence of North American orthopoxviruses in nature is unknown and may be more difficult to ascertain due to wide spread use of vaccinia virus recombinant vaccines in the wild. A real time PCR assay was developed to allow for highly sensitive and specific detection of North American orthopoxvirus DNA in animal tissues and bodily fluids. This method is based on the amplification of a 156 bp sequence within a myristylated protein, highly conserved within the North American orthopoxviruses but distinct from orthologous genes present in other orthopoxviruses. The analytical sensitivity was $1.1 \mathrm{fg}$ for Volepox virus DNA, $1.99 \mathrm{fg}$ for Skunkpox virus DNA, and 6.4 fg for Raccoonpox virus DNA with a 95\% confidence interval. Our assay did not cross-react with other orthopoxviruses or ten diverse representatives of the Chordopoxvirinae subfamily. This new assay showed more sensitivity than tissue culture tests, and was capable of differentiating North American orthopoxviruses from other members of Orthopoxvirus. Thus, our assay is a promising tool for highly sensitive and specific detection of North American orthopoxviruses in the United States and abroad.
\end{abstract}

Keywords: orthopoxviruses, North American orthopoxviruses, myristylated protein, real time PCR

\section{Background}

The family Poxviridae is divided in two subfamilies: Entomopoxvirinae, which infect insects, and Chordopoxvirinae, which infect vertebrates[1]. Genera of the subfamily Chordopoxvirinae that may cause human infections include Orthopoxvirus, Parapoxvirus, Molluscipoxvirus and Yatapoxvirus[1,2]. The genus Orthopoxvirus (OPXV) is the most relevant in terms of human public health concerns and includes viruses that have been associated with severe febrile, rash illness in humans. Its members include: Variola virus, a solely human pathogen and the etiological agent of smallpox [2-4]; Monkeypox virus, a zoonotic disease that causes a generalized rash similar to smallpox with up to $10 \%$ case fatality rate[5]; Vaccinia virus (VACV), the smallpox vaccine which can produce generalized illness in immunocompromised individuals[6]; and Cowpox virus, another zoonotic disease which can cause generalized illness in immunocompromised individuals $[6,7]$. In

\footnotetext{
* Correspondence: hfa5@cdc.gov

Centers for Disease Control and Prevention, National Center for Emerging and Zoonotic Infectious Diseases, Division of High-Consequence Pathogens and Pathology, Poxvirus and Rabies Branch, Atlanta, GA 30333, USA
}

immunocompetent individuals, infection with vaccinia or cowpox viruses usually only results in localized rash illness. The other viruses within this genus are not currently known to cause human disease.

The last few decades have seen the description of three orthopoxviruses (OPXVs) from North America named after the animal species in which they were originally isolated: Raccoonpox virus, Volepox virus, and Skunkpox virus[8-11]. These OPXVs are collectively referred to as North American OPXVs (NA OPXVs). Subsequent work has determined that the NA OPXVs species are a monophyletic group that is the most genetically divergent within the OPXV genus[11]. Raccoonpox virus (RCNV) was isolated for the first time in Maryland, 1961, from two out of 97 healthy looking raccoons (Procyon lotor). In the same study, an orthopoxvirus seroprevalence rate of $23 \%$ (22/92) was observed[8]. Volepox virus (VPXV) was first isolated from a California vole (Microtus californicus) foot scab in 1985[12], and later from a Piñon mouse (Peromyscus truei) scab in 1988[10], both in San Mateo county, California. Skunkpox virus (SKPV) has been isolated only once from an ill skunk in Washington in 1978[11]. Few studies have been conducted regarding

\section{(Ciomed Central}


the ecology, pathology and pathogenicity of these NA OPXVs[9-14], but their prevalence and role as etiological agents of potential zoonotic diseases remain unknown.

The development of a highly specific and sensitive assay for detection of NA OPXVs is critical to the understanding of NA OPXVs incidence and prevalence in North American mammals. In addition, the effect of NA OPXVs endemicity on the immunization of wildlife populations against other infectious diseases, using VACV vectored vaccines, is unknown. Orthopoxvirusvectored recombinant wildlife vaccines [e.g. rabies, plague[14-17]], could have the potential to recombine with NA OPXVs in nature. The use of this assay will enable detailed studies of NA OPXVs prevalence, pathology and pathogenesis in their putative host species.

Additional studies using these specific determinations of NA OPXVs prevalence and incidence rate will inform subsequent studies evaluating the possible interference of NA OPXVs disease and immunity, with disease control strategies in which orthopoxvirus-vectored vaccines target the same susceptible wildlife species.

\section{Methods}

\section{Alignment and phylogenetic reconstruction}

Amino acid sequences of the G9R gene were aligned using the ClustalW accessory in BioEdit (Figure 1) and translated back into the original nucleotide sequence for phylogenetic analysis. A heuristic tree search was carried out in PAUP* 4.0 b10 over 1000 replicates.

Bootstrap values were calculated from 1000 bootstrap replicates of 1000 random addition sequence replicates each. One of two most parsimonious trees is illustrated in Figure 2.

\section{Primer, probe design and assay conditions}

We designed a real time PCR (rt-PCR) assay based on TaqMan $^{\circledR}$ chemistry and technology using the VPXV 086 gene, SKPV 086 gene and RCNV 070 gene (ortholog of the VACV Copenhagen G9R). The targeted gene encodes for the myristylated protein, which is an essential component for cell membrane fusion and entry[18]. The orthologous genes for all viruses included in this study were aligned using BioEdit to pick the target area on the basis of conservation and GC content. The primers G9R-NA OPXV forward (5'YGG-ACC-RGG-AGG-TCT-TTCTGC-ATT 3'), G9R-NA OPXV reverse (5'TCT-GGCCAA-CAT-GAT-TCT-AAT-ACT-GCR-TC 3'), and G9R-NA OPXV probe (5'FAM AG-GGA-ACG-VTAYAA-TGG-YAC-YGC-TCC-CAA-YTG-CTG-TCGCAC-TTT-BHQ1 3') were designated to amplify a $156 \mathrm{bp}$ fragment from a highly conserved region of the gene (Figure 1). Primers and probe were synthesized in the Biotechnology Core facility (CDC, Atlanta, GA), utilizing standard phosphoramidite chemistry. The nomenclature for the degenerated positions in the primers and probe designed was based on IUPAC. The probe contained the fluorophore (FAM) at the 5' end and the black hole quencher at the 3' end. DNA amplification was carried out using default rt-PCR thermal conditions for the ABI7900 (Applied Biosystem, Foster City, Ca), briefly: one cycle of $95^{\circ} \mathrm{C}$ for 10 minutes, followed by 40 cycles of $95^{\circ} \mathrm{C}$ for 15 seconds and $60^{\circ} \mathrm{C}$ for 1 minute. PCR amplification is based on fluorescent emission after annealing/ elongation $\left(60^{\circ} \mathrm{C}\right)$. The assay was performed in a final volume of 25 ul per well containing 12.5 ul of TaqMan ${ }^{\circledR}$ Universal PCR Master Mix (Applied Biosystem, New Jersey, USA), $4.5 \mathrm{ul}$ of deionized distilled water, $1 \mathrm{ul}$ of each forward and reverse primer at a concentration of $20 \mathrm{uM}$, $1 \mathrm{ul}$ of probe at a concentration of $10 \mathrm{uM}$, and $5 \mathrm{ul}$ of template DNA.

\section{Analytical sensitivity and specificity of G9R-NA OPXV rt- PCR assay}

A total of thirteen chordopoxviruses, which comprised seven old world OPXVs, three NA OPXVs, and three from different genera, were included to test the analytical specificity of the assay (Table 1). The latter three included one Parapoxvirus, one Leporipoxvirus and one Yatapoxvirus. All viruses in the panel (with the exception of the squirrel fibroma virus, which was a crude cell culture extract), were propagated via cell culture and purified by two sucrose cushions[19-21]. Total viral DNA was extracted using Qiagen tissue kits on the BioRobot ${ }^{\mathbb{R}}$ EZ1 workstation, according to the manufacturer's instructions, and later quantified by spectrophotometry using Qubit ${ }^{\mathrm{TM}}$ Quantitation Platform by Invitrogen ${ }^{\mathrm{TM}}$. All viruses in the panel were serially diluted with deionized distilled water until obtaining appropriate working concentrations. To determine analytical specificity of our assay, the total DNA concentration was adjusted to $2 \mathrm{ng}$ per $5 \mathrm{ul}$ for all the thirteen viruses in the panel, and the rt-PCR assay was run in triplicate for each sample.

Analytical sensitivity was determined by using DNA of the three NA OPXVs at seven different concentrations, $40 \mathrm{fg}, 4 \mathrm{fg}, 2 \mathrm{fg}, 1 \mathrm{fg}, 0.5 \mathrm{fg}, 0.25 \mathrm{fg}$, and $.125 \mathrm{fg} / \mathrm{ul}$. The rt-PCR for each concentration was run in 24 replicates. A statistical probit analysis, a non-linear regression model, using commercial software SAS 9.2 (SAS Institute, Cary, NC, USA) was done to determine the detection limit of each assay with $95 \%$ confidence.

\section{Animal specimen collection and preparation}

Peromyscus californicus (Peromyscus Genetic Stock Center, University of South Carolina) were infected intranasally with $10 \mathrm{ul}$ of volepox virus at a concentration of $1.6 \times 10^{3}$ PFU or mock infected with $10 \mathrm{ul}$ of phosphate-buffered saline (PBS). Pre-screening of the animals 


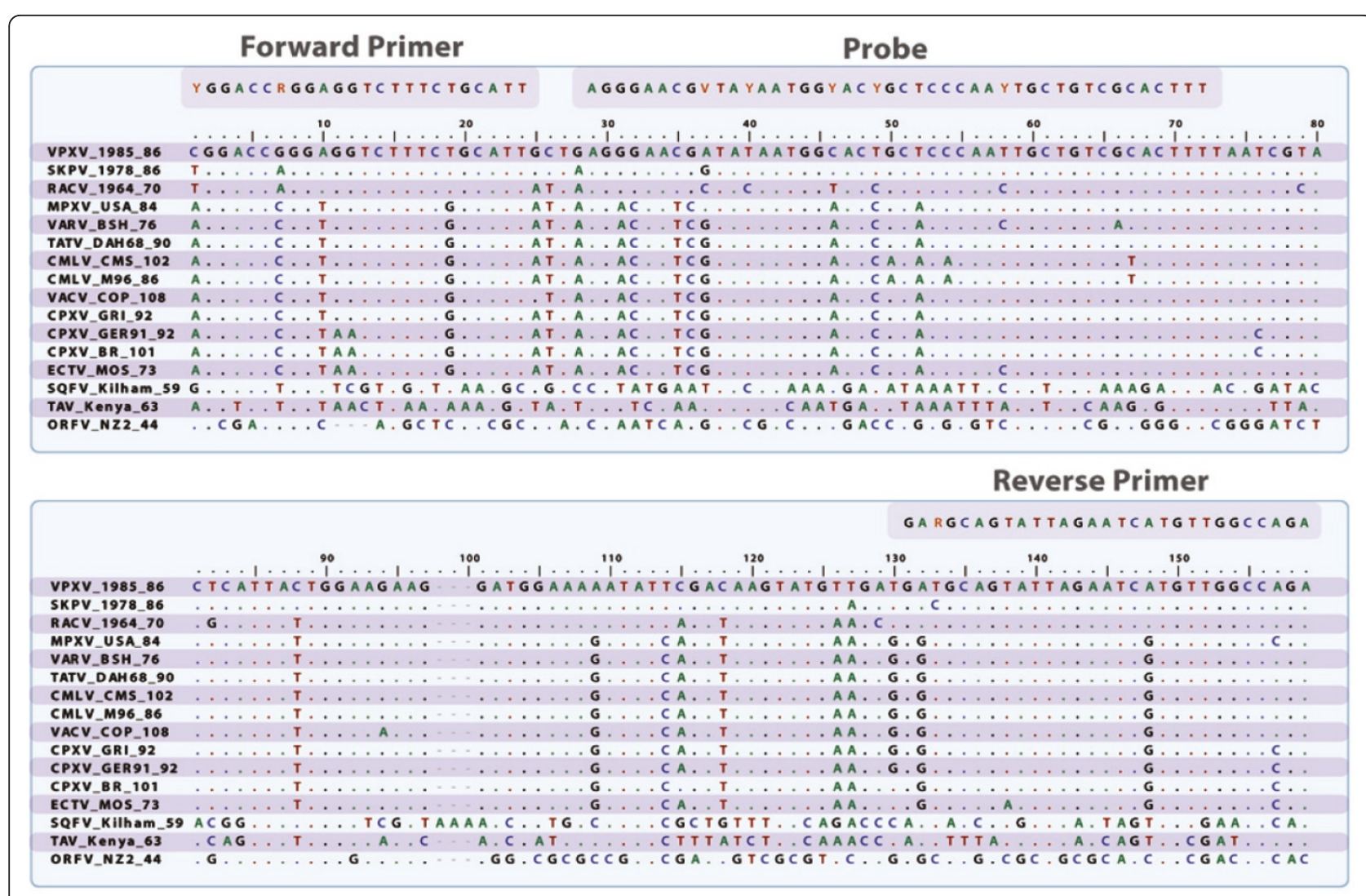

Figure 1 Alignment of the $156 \mathrm{bp}$ target area used to design the primers and probe of G9R NA OPXV rt-PCR assay

included evaluation of anti-VPXV and anti-VACV immunoglobulin type $\mathrm{G}$ by modified ELISA with 1:100 dilution of animal serum, and orthopoxviral DNA in EDTA blood, oral swab, ocular swab and anal swabs by rt-PCR as previously described[22,23]. Specimens taken from live animals (blood, oral swab, ocular swab, and anal swab), and during necropsy (spleen, gonad, kidney, submandibular lymph node, supradrenal gland, brain, liver and lung) were performed/collected in accordance with CDC Institutional Animal Care and Use Committee (IACUC) guidelines under the approved protocol 2126 CARMOUC. In some animals, additional organs were taken at necropsy if lesions or signs of disease were observed (skin, tongue, bladder, intestine and/or pancreas) (Table 2). A total of 187 samples, from different tissues and bodily fluids, were collected from animals with clear signs of disease (for example: conjunctivitis, ruffled hair, skin lesions, crusty noses, apathy and/or swollen faces) on days 6, 7 and 8 post-infection as well as 45 tissue samples and bodily fluids from healthy, never infected Peromyscus californicus. Swabs were hydrated for 5 minutes with $400 \mathrm{ul}$ of PBS, and transferred to SETS tubes (Swab Extraction Tube System, Roche, Cata$\log$ No. 3315568). The SETS tubes were centrifuged in the VWR Galaxy Mini centrifuge (6000 rpm) for $1 \mathrm{~min}$ ute to collect the eluant for DNA extraction and cell culture. The tissue samples were suspended in $1 \mathrm{ml}$ of PBS and a sterile SPEX bead was added. The GenoGrinder 2000 (SPEX Sample Prep) was used following the manufacturer's instructions to triturate the tissue for later cell culture and DNA extraction using the Qiagen tissue kits on the BioRobot ${ }^{\circledR}$ EZ1 workstation, according to the manufacturer's instructions.

\section{Detection of viable OPXV in animal samples through tissue cell culture techniques}

BSC-40 cell monolayers (African green monkey kidney cell line) were inoculated with 10 -fold dilutions of sonicated tissue extract or swab elute. Infected cells were incubated at $36^{\circ} \mathrm{C}$ in a $6 \% \mathrm{CO}_{2}$ atmosphere in semi solid medium (RPMI + 1\% Carboxymethylcellulose). Cell infection was monitored microscopically by observation of OPXV specific cytopathic effect (CPE). At $48 \mathrm{~h}$ post inoculation, cells were stained with crystal violet to reveal plaques to determine the viral titer $(\mathrm{PFU} / \mathrm{ml})$. A total of 187 putative positive, and 45 negative samples were examined for the presence of viable virus by cell culture isolation. These samples were also used for 


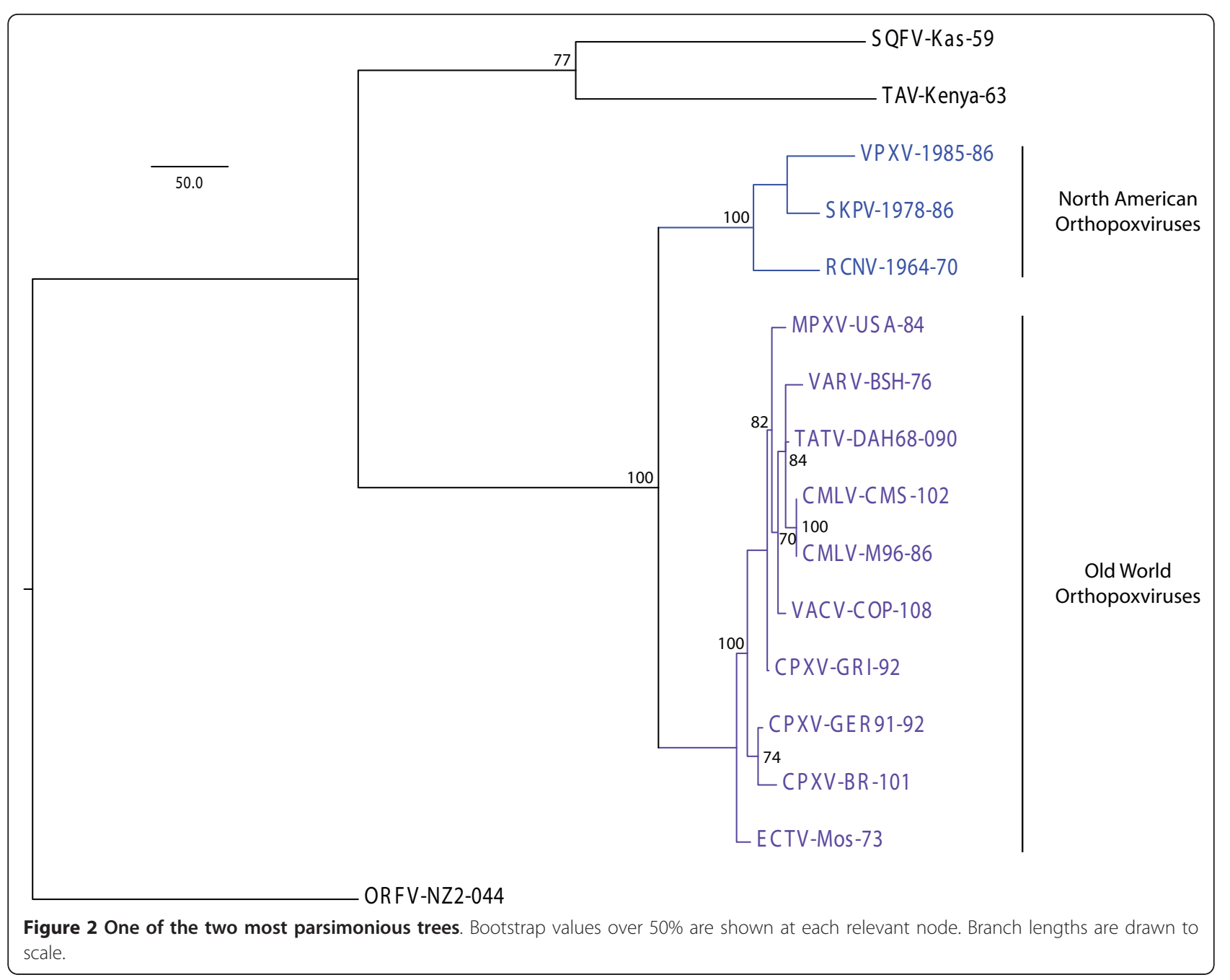

Table 1 Panel of viral DNA used to validate the G9R-NA OPXV rt-PCR assay

\begin{tabular}{|c|c|c|c|c|c|}
\hline Old World viruses & Sample ID & Accession No. & Ortholog & Viral Prep. & $2 \mathrm{ng}^{*}$ \\
\hline Camelpox & CMLV-V78 I & Not available & Not available & Pure & $\mathrm{ND}$ \\
\hline Cowpox & CPXV-Sweden & Not available & Not available & Pure & ND \\
\hline Ectromelia & ECTV-MOS & NC_004105 & 73 & Pure & ND \\
\hline Monkeypox & MPXV-USA & DQ011157 & 84 & Pure & ND \\
\hline Orf & ORFV-NZ2 & DQ184476 & 44 & Pure & ND \\
\hline Squirrel Fibroma & SQFV-Kilham & Not available & 59 & Crude & ND \\
\hline Tanapox & TAV-Kenya & NC_009888 & 63 & Pure & ND \\
\hline Taterapox & TATV-DAH68 & NC_008291 & 90 & Pure & ND \\
\hline Vaccinia & VACV-COP & M35027 & 108 & Pure & ND \\
\hline Variola & VARV-BSH & L22579 & 76 & Pure & ND \\
\hline \multicolumn{6}{|c|}{ North American viruses } \\
\hline Raccoonpox & RCNV-1964 & FJ807746-54 & 70 & Pure & 17 \\
\hline Skunkpox & SKPV-1978 & FJ807755-63 & 86 & Pure & 17 \\
\hline Volepox & VPXV-1985 & FJ807737-45 & 86 & Pure & 16 \\
\hline
\end{tabular}

*The average of the cycle when fluorescence crossed the threshold $(\mathrm{Ct})$ for each positive sample is shown. ND, not detected. 
Table 2 Samples from $P$. californicus either negative control (un) or infected with volepox virus (inf) were tested with G9R-NA OPXV rt-PCR assay

\begin{tabular}{|c|c|c|c|c|c|c|c|c|}
\hline \multirow[t]{2}{*}{ Specimen } & \multicolumn{2}{|c|}{ Day 6} & \multicolumn{2}{|c|}{ Day 7} & \multicolumn{2}{|c|}{ Day 8} & \multicolumn{2}{|c|}{ Total No. of specimens } \\
\hline & (Inf) & (un) & (inf) & (un) & (inf) & (un) & (inf) & (un) \\
\hline Blood & 4 & 1 & 3 & 1 & 2 & 1 & 9 & 3 \\
\hline Oral swab & 6 & 1 & 5 & 1 & 7 & 1 & 18 & 3 \\
\hline Ocular swab & 6 & 1 & 8 & 1 & 2 & 1 & 13 & 3 \\
\hline Anal swab & $5 \sim$ & 1 & $3 \sim$ & 1 & 2 & 1 & 13 & 3 \\
\hline Spleen & 6 & 1 & 5 & 1 & 2 & 1 & 13 & 3 \\
\hline Gonad & 6 & 1 & 5 & 1 & 2 & 1 & 13 & 3 \\
\hline Kidney & 6 & 1 & 5 & 1 & 2 & 1 & 13 & 3 \\
\hline Lymph node & 6 & 1 & 5 & 1 & 2 & 1 & 13 & 3 \\
\hline Supradrenal & 6 & 1 & 4 & 1 & 2 & 1 & 12 & 3 \\
\hline Brain & 6 & 1 & 5 & 1 & 2 & 1 & 14 & 3 \\
\hline Liver & 6 & 1 & 5 & 1 & 2 & 1 & 14 & 3 \\
\hline Lung & 6 & 1 & 5 & 1 & 2 & 1 & 14 & 3 \\
\hline Skin lesion & 5 & 1 & 2 & 1 & 10 & 1 & 14 & 3 \\
\hline Tognue lesion & 5 & 1 & 2 & 1 & NA & 1 & 7 & 3 \\
\hline Intestine lesion & NA & 1 & 2 & 1 & NA & 1 & 2 & 3 \\
\hline Bladder & NA & NA & 2 & NA & 1 & NA & 3 & NA \\
\hline Pancreas & NA & NA & 1 & NA & 1 & NA & 2 & NA \\
\hline Number of positive/tested & $79 / 80$ & $0 / 15$ & $64 / 66$ & $0 / 15$ & $41 / 41$ & $0 / 15$ & $184 / 187$ & $0 / 45$ \\
\hline
\end{tabular}

DNA was detected in all samples from infected animals (inf) but 3 anal swabs (1 from Day 6 and 2 from Day 7).

DNA was not detected in any negative control (un). NA, not applicable.

determining analytical sensitivity and specificity of the rt-PCR

\section{Results}

Analytical specificity of G9R-NA OPXV rt-PCR assay

The orthopoxviruses are all very closely related[11]. Yet the NA OPXVs cluster into their own phylogenetic subclade, as shown in the alignment of the myristylated protein ortholog (Figure 2). Our NA OPXV rt-PCR assay was validated using at least one representative strain of each species of OPXV as well as one strain from the genera Parapoxvirus, Leporipoxvirus, and Yatapoxvirus (Table 1 ). The assay consistently detected all three NA OPXVs at 2 ng total DNA (equivalent to $>8$ 9 million virus genomes), with threshold cycle (Ct) values ranging from 16 to 17 (Table 1 ). The purity of these viral preparations was verified using a real-time PCR assay to detect contaminating cellular DNA (RNase P), which did not cross-react with any of the NA OPXVs DNA preparations (data not shown). The NA OPXV rt-PCR assay demonstrated specificity for NA OPXVs, not reacting with the other seven OPXVs or three non-orthopoxvirus members of Chordopoxviridae when tested at similar concentrations (Table 1).

\section{Analytical sensitivity of G9R-NA OPXV rt-PCR assay}

To determine the analytical sensitivity of the assay for each of the NA OPXVs, 24 replicates of seven different concentrations were conducted with the NA OPXV rt-
PCR assay. The assay was least sensitive for RCNV; DNA was detected in all 24 replicates down to $10 \mathrm{fg}$ of DNA (Table 3). For $5 \mathrm{fg}$ of total DNA, 20 out of 24 replicates yielded positive results, and for $2.5 \mathrm{fg}$, five out of 24 replicates were detected as positive. The assay showed higher sensitivity for SKPV DNA, with positive results in all 24 replicates down to $2.5 \mathrm{fg}$ of total DNA (Table 3). At $1.25 \mathrm{fg}, 18$ of 24 replicates were detected as positive, and at $0.625 \mathrm{fg}$, eleven of 24 replicates were positive. The assay proved its highest sensitivity for VPXV DNA. All 24 replicates at concentrations as low as $2.5 \mathrm{fg}$ were detected (Table 3). At $1.25 \mathrm{fg}$ of total VPXV DNA, the assay detects 23 of the 24 replicates, and at $0.625 \mathrm{fg}, 19$ of the replicates were positive. The average $\mathrm{Ct}$ values from all positive samples are shown in

Table 3 G9R-NA OPXV assay sensitivity to North American OPXV DNA

\begin{tabular}{|c|c|c|c|c|c|c|c|c|}
\hline Virus & $\begin{array}{c}\text { DNA } \\
\text { (fg) }\end{array}$ & 200 & 20 & 10 & 5 & 2.5 & 1.25 & 0.625 \\
\hline Raccoonpox & Pure & 33 & 36.5 & 37.9 & $\begin{array}{r}38.9 \\
(20)\end{array}$ & $\begin{array}{c}39.4 \\
\text { (5) }\end{array}$ & NT & NT \\
\hline Skunkpox & Pure & 28.9 & 32.7 & 34 & 35 & 36 & $\begin{array}{l}37.8 \\
(18)\end{array}$ & $\begin{array}{l}39.2 \\
(11)\end{array}$ \\
\hline Volepox & Pure & 30.4 & 33.9 & 35.2 & 36.1 & 37.4 & $\begin{array}{l}38.8 \\
(23)\end{array}$ & $\begin{array}{r}39.4 \\
(19)\end{array}$ \\
\hline
\end{tabular}

The average of the cycle when fluorescence crossed the threshold $(\mathrm{Ct})$ for each positive sample is shown.

NT, not tested (number of sample detected from 24 replicates). DNA amounts are shown in $\mathrm{fg}$. 
Table 3. Based on RNaseP assay results, we can confidently calculate the number of viral genomes detected based on mass, since there was no detectable cellular DNA contamination in our preparations. The statistical analysis (probit) indicated that the assay is capable of detecting with 95\% confidence, $1.1 \mathrm{fg}$ of VPXV DNA ( $\sim 5$ genomes), $1.99 \mathrm{fg}$ of SKPV DNA ( $\sim 8$ genomes) and $6.4 \mathrm{fg}$ of RCNV total DNA ( 29 genomes) under the cycling conditions, primers and probes described (Figure 3).

\section{Specificity and sensitivity of detection of NA OPXV DNA in animal samples by rt-PCR}

Analysis of all samples (blood, oral swab, ocular swab and anal swabs) taken prior to infection tested negative for OPXV DNA by rt-PCR, and anti-VPXV and antiVACV IgG by modified ELISA[22,23](data not included in the assay evaluation). One hundred and eighty four out of 187 specimens collected at days 6,7 and 8 postinfection from different tissues and bodily fluids generated $\mathrm{Ct}$ values in the positive range (between 15 and 40) for our NA OPXV rt-PCR assay, indicating the presence of DNA specific for a NA OPXV (Table 2). Only three anal swabs out of 13 taken were negative, and may contain levels of viral DNA under the detection threshold for our assay $(1.1 \mathrm{fg})$. All 45 samples from the naïve (PBS mock infected) animals were negative by our G9RNA OPXV rt-PCR assay (Table 2).

\section{Comparative detection of NA OPXV in animal samples with cell culture versus rt-PCR}

One hundred and seventy-eight samples out of a total of $184 \mathrm{rt}-\mathrm{PCR}$ positive samples demonstrated detectable $\mathrm{CPE}$ in a single passage on BSC-40 cells. All these samples had a Ct values of 37 or below which, based on the quantification from the standard curve, would equate to a minimum of 45 genomes of VPXV DNA. Six samples out of $184 \mathrm{rt}-\mathrm{PCR}$ positives with Ct values of 38 and above were discordant with cell culture viability results; in these samples no viable virus was detected and the estimated number of genomes is less than 45 . All 45 samples from naïve animals were confirmed negative by both rt-PCR and cell culture. When comparing cell culture with rt-PCR results, samples with $\mathrm{Ct}$ values equal or lower than 37 were positive for VPXV growth, and samples with Ct values 38 and above did not show evidence of viable VPXV.

\section{Discussion}

North American OPXVs have been detected previously using the Low GC Pan-Pox standard end point PCR assay[24]. However, the sensitivity of this standard PCR assay is lower ( 10,000 genome copies) and more time intensive than our rt-PCR assay for the detection of NA OPXVs ( $<30$ genome copies). The G9R-NA OPXV assay is a high throughput assay better suited for screening proposes either in the field or laboratory experiments that aim to detect low levels of NA OPXV DNA. The assay presented here showed an analytical sensitivity of $1.1 \mathrm{fg}$ of VPXV DNA, $1.99 \mathrm{fg}$ of SKPV DNA and $6.4 \mathrm{fg}$ of RCNV DNA, which is equivalent to approximately five, eight, and 29 viral genomes respectively. Our assay also demonstrated high specificity, capable of discriminating all NA OPXVs from several other members of the genus Orthopoxvirus and the subfamily Chordopoxvirinae. Since our assay does not cross-react with $\mathrm{VACV}$, it is possible to determine if wild animals are potentially co-infected with a NA OPXV and a VACV vector vaccine (ex. Rabies, plague). The presence of more than one OPXV in the same individual may mask the detection of the other virus when detection assays are broadly reactive. The G9R-NA OPXV rt-PCR assay will be useful for future studies on the efficacy of VACV vector vaccines within wild animal populations where NA OPXVs are endemic.

This rt-PCR assay may also offer great utility in confident detection of NA OPXVs DNA within tissues and bodily fluid samples obtained from infected animals. Its sensitivity and specificity significantly surpasses that of tissue cell culture. Unlike tissue cell culture, our NA
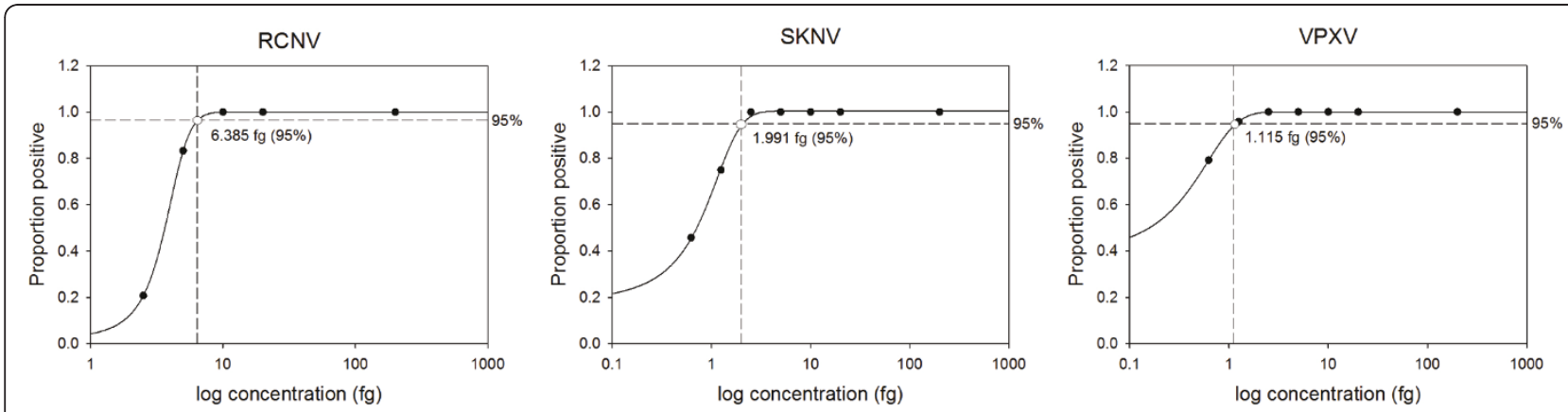

Figure 3 Amount of viral DNA detected by the G9R NA OPXV rt-PCR assay with $95 \%$ confidence based on the probit statistical analysis. 
OPXV rt-PCR assay is capable of quickly differentiating between Eurasian OPXV and NA OPXV. Although tissue culture is still the only means to detect viable viral particles, our assay demonstrates greater sensitivity than tissue culture, most likely due to the ability to detect viral DNA from damaged viral particles or DNA remnants. Previous OPXV studies done during the US monkeypox outbreak in 2003, also found rt-PCR assays to be more sensitive than tissue culture analysis $[22,25,26]$. Our assay detected six samples as positive that did not contain viable virus, possibly due to compromised integrity of the viral particle by either the animal immune system or by an external factor during the sample collection or processing. A benefit of such a sensitive assay is the ability to prove that animals were infected even when viable virus is no longer present or viral isolation is unable to be performed.

\section{Conclusions}

The sensitivity and specificity of this assay makes it a highly useful tool for detecting NA OPXV in field studies as well as a monitoring tool in pathogenesis studies. Our rt-PCR assay is a more sensitive, rapid and less labor intensive method for the specific identification of NA OPXV DNA within a sample, allowing prompt diagnosis of infection.

\section{Acknowledgements \\ The authors want to thank Kevin L. Clark for the development of the manuscript's figures and tables.}

\begin{abstract}
Authors' contributions
NG-R conceived of the study, participated in its design, assay validation, sample processing, data analysis, and drafted the manuscript. AV-V performed the structural gene alignments, primer design and drafted the manuscript. SW assisted in acquiring animal samples and processing the samples. GE carried out the phylogenetic reconstructions and drafted the manuscript. DC contributed to study design and obtained funds for the research. $\mathrm{CH}$ performed statistical analysis. YL established the rt-PCR settings to optimize the assay. KK and ID contributed to study design and provided useful manuscript review. VO designed molecular validation of the rt-PCR assay and contributed to final manuscript version. All authors read and approved the final manuscript.
\end{abstract}

\section{Competing interests}

The authors declare that they have no competing interests.

Received: 1 April 2011 Accepted: 20 June 2011 Published: 20 June 2011

\section{References}

1. Mayo M, Maniloff J, Dusselberger U, Ball L, CM F: Virus taxonomy: VIIIth report of the International Committee on Taxonomy of Viruses. Academic Press, New York 2005.

2. Fenner F: Poxviruses. In Virology.. Second edition. Edited by: Fields BN. New York: Raven Press; 1990:2113-2131.

3. Li Y, Carroll DS, Gardner SN, Walsh MC, Vitalis EA, Damon IK: On the origin of smallpox: correlating variola phylogenics with historical smallpox records. PNAS 2007, 104:15787-15792.

4. Fenner F, Henderson D, Arita I, Jezek Z, Ladnyi I: The epidemiology of smallpox. Smallpox and its eradication Geneva: World Health Organization 1998, 169-208
5. Jezek Z, Fenner F: Human Monkeypox New York, NY: Karger; 1988.

6. Jacobs BL, Langland JO, Kibler KV, Denzler KL, White SD, Holechek SA, Wong S, Huynh T, Baskin CR: Vaccinia virus vaccines: past, present and future. Antiviral Research 2009, 84:1-13.

7. Fenner F: Cowpox virus. Virus Infections of Rodents and Lagomorphs, ed Osterhaus ADME Elsevier Science, Amsterdam; 1994, 27-32.

8. Alexander A, Flyger V, Herman Y, McConnell S, Rothstein N, Yager R: Survey of wild mammals in a Chesapeake Bay area for selected zoonoses. Journal of Wildlife Diseases 1972, 8:119-126.

9. Cavallaro KF, Esposito JJ: Sequences of the raccoon poxvirus hemagglutinin protein. Virology 1992, 190:434-438.

10. Knight JC, Goldsmith CS, Tamin A, Regnery RL, Regnery DC, Esposito JJ: Further analyses of the orthopoxviruses volepox virus and raccoon poxvirus. Virology 1992, 190:423-433.

11. Emerson GL, Li Y, France MA, Olsen-Rasmussen MA, Khristova ML, Govil D, Sammons SA, Regnery RL, Karem KL, Damon IK, Carroll DS: The phylogenetics and ecology of the orthopoxviruses endemic to North America. PLOS ONE 2009, 4:e7666.

12. Regnery DC: Isolation an partial characterization of an orthopoxvirus from a California vole (Microtus californicus). Archieves of Virology 1987, 94:159-162.

13. Li Y, Ropp SL, Zaho H, Damon IK, Esposito JJ: Orthopoxvirus pan-genomic DNA assay. Journal of Virological Methods 2007, 141:154-165.

14. Root JJ, McLean RG, Slate D, MacCarthy KA, Osorio JE: Potential effect of prior raccoonpox virus infection in raccoons on vaccinia-based rabies immunization. BMC Immunology 2008, 9:57.

15. Brochier B, Blancou J, Thomas I, Languet B, Artois M, Kieny MP, Lecocq JP, Costy F, Desmettre P, Chappuis G, Pastoret PP: Use of recombinant vaccinia-rabies glycoprotein virus for oral vaccination of wildlife against rabies: innocuity to several non-target bait consuming species. Journal of Wildlife Diseases 1989, 25:540-547.

16. Rocke TE, Smith SR, Stinchcomb DT, Osorio JE: Immunization of blacktailed prairie dog against plague through consumption of vaccine-laden baits. Journal of Wildlife Diseases 2008, 44:930-937.

17. Mencher JS, Smith SR, Powell TD, Stinchcomb DT, Osorio JE, Rocke TE: Protection of black-tailed prairie dogs (Cynomys ludovicianus) against plague after voluntary consumption of baits containing recombinant raccoon poxvirus vaccine. Infecction and Immunity 2004 72:5502-5505

18. Ojeda S, Domi A, Moss B: Vaccinia virus G9 protein is an essential component of the poxvirus entry-fusion complex. Journal of Virology 2006, 80:9822-9830.

19. Esposito JJ, C KJ: Orthopoxvirus DNA: a comparision of restriction profiles and maps. virology 1985, 143:51.

20. Esposito J, Obijeski J, Nakano J: Orthopoxvirus DNA: strain differentiation by electrophoresis of restriction endonuclease fragmented virion DNA. Virology 1978, 89:53-66.

21. Seki M, Oie M, Ichihashi $Y$, Shida H: Hemadsorption and fusion inhibition activities of hemagglutinin analyzed by vaccinia virus mutants. Virology 1990, 175:372-384

22. Hutson CL, Olson VA, Carroll DS, Abel JA, Hughes CM, Braden ZH, Weiss S, Self J, Osorio JE, Hudson PN, et al: A prairie dog animal model of systemic orthopoxvirus disease using West African and Congo Basin strains of monkeypox virus. Journal of General Virology 2009, 90:323-333.

23. Li Y, Olson VA, Laue T, Laker MT, Damon IK: Detection of monkeypox virus with real-time PCR assays. Journal of Clinical Virology 2006, 36:194-203.

24. Li Y, Meyer H, Zaho H, Damon IK: GC content-based pan-pox universal PCR assays for poxvirus detection. Journal of Clinical Microbiology 2010, 48:268-276.

25. Hutson CL, Lee KN, Abel J, Carroll DS, Montgomery JM, Olson VA, Li Y, Davidson W, Hughes C, Dillon M, et al: Monkeypox zoonotic associations: insights from laboratory evaluation of animals associated with the multistate US outbreak. The American Journal of Tropical Medicine and Hygiene 2007, 76:757-767.

26. Hutson CL, Abel J, Carroll DS, Olson VA, Braden Z, Hughes C, Dillon M, Hopkins C, Karem KL, Damon IK, Osorio JE: Comparison of West African and Congo Basin Monkeypox Viruses in BALB/C and C57BL/6 Mice. PLoS one 2010, 5:e8912.

doi:10.1186/1743-422X-8-313

Cite this article as: Gallardo-Romero et al.: Detection of North American

orthopoxviruses by real time-PCR. Virology Journal 2011 8:313. 